\title{
AN OVERVIEW OF PHARMACEUTICAL AND BIOLOGICAL PRODUCT QUALITY CONTROL
}

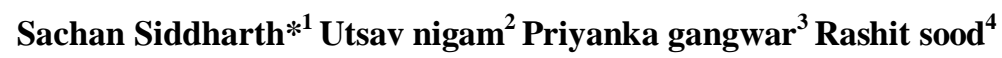 \\ ${ }^{1}$ Rass Biosolution Pvt. Ltd Kanpur, India \\ ${ }^{2}$ Lovely Professional University Punjab, India \\ ${ }^{3}$ Indian Institute of Pulse Research Kanpur, India \\ ${ }^{4}$ Hetero Labs Ltd Baddi Himanchal Pradesh, India \\ *Corresponding author email: Siddharthsachan4@gmail.com
}

\begin{abstract}
Quality control (QC) is a procedure or set of procedures intended to ensure that a manufactured product or performed service adheres to a defined set of quality criteria or meets the requirements of the client or customer. QC is similar to, but not identical with, quality assurance (QA). There are various quality control parameters and guidelines which ensure us to deliver a slandered and contamination free product in the market. These quality control procedure and guidelines ensure the product development in the global slandered. In past years the role of quality control is increased in pharmaceutical and biotechnology industry. The maintenance of product quality is maintained by these procedure and guideline. Here we give a analytical description about why quality control procedures are important in the field of pharmaceutical and biological product manufacturing and what are the similarity between these procedures in both industries.
\end{abstract}

Key words- QC, Pharmaceutical products, Biological products

\section{INTRODUCTION}

Quality control (QC) is a procedure or set of procedures intended to ensure that a manufactured product or performed service adheres to a defined set of quality criteria or meets the requirements of the client or customer. QC is similar to, but not identical with, quality assurance (QA). QA is defined as a procedure or set of procedures intended to ensure that a product or service under development (before work is complete, as opposed to afterwards) meets specified requirements. QA is sometimes expressed together with QC as a single expression, quality assurance and control (QA/QC). ${ }^{1}$

A major aspect of quality control is the establishment of well-defined controls. These controls help standardize both production and reactions to quality issues. Limiting room for error by specifying which production activities are to be completed by which personnel reduces the chance that employees will be involved in tasks for which they do not have adequate training. ${ }^{2}$

\section{IMPORTENCE OF QUALITY CONTROL IN PHARMACEUTICAL INDUSTRY}

Quality control is essential in the drug development program to ensure that the drug substance and other raw materials are suitable for use in your drug product and to ensure that the drug product manufactured meets the highest quality standards which is required for this industry. The Quality Control process is involved throughout the entire development process, from drug substance and raw material control, through intermediate drug product testing, to finish drug product release testing and stability studies ${ }^{3}$.

C 2011, JDDT. All Rights Reserved
In pharmaceuticals without assurance that these medicines which are required for the priority health need and they meet the excepted standard of quality safety and efficacy, any health service is evidently compromised. In developing countries considerable administrative and technical effort is directed to ensuring that patients receive effective medicines of good quality.

\section{ADVANTAGES OF QUALITY CONTROL IN PHARMACEUTICAL INDUSTRY}

Quality control always has a advantage in pharmaceutical industry. It help to reduce costs by cutting down wastes caused by the production of defective products. It also enable to manufacturer to comply with quality standard prescribed by the government. A good quality control is always help to improve the brand image of any organization.

\section{IMPORTENCE OF A MODERN AND EFFECTIVE PQS}

A modern effective PQS made some significant changes in external business environment. It can survive in great competition with low coast sources.

\section{OBJECTIVE OF QUALITY CONTROL SYSTEM IN PHARMACEUTICAL INDUSTRY}

Achieve Product Realization

Establish and Maintain a State of Control

Facilitate Continual Improvement 


\section{WHAT ARE THE BIOLOGICAL PRODUCTS}

A virus, therapeutic serum, toxin, antitoxin, vaccine, blood, blood component or derivative, allergenic product, or analogous product applicable to the prevention, treatment, or cure of a disease or condition of human beings. Note: Biological products also include immunoglobulin products, monoclonal antibodies, products containing cells or microorganisms, and most proteins intended for therapeutic use. ${ }^{4}$

\section{BIOLOGICAL PRODUCTS QUALITY CONTROL}

The quality of biological products is a major aspect and a prime responsibility of any manufacturer. It is also the responsibility of regulatory authority of a particular country that insures that the production units follow the correct procedure of quality control. The countries where biological products are manufactured, it is responsibility of government authorities' to properly evaluate the manufacturing facility and the quality control procedures. It is essential for a biological products manufacturing facility to meet the national or international specifications for the product manufacturing. The countries where biological products are not manufactured the alternative methods are acceptable for the safety and efficiency of the products. ${ }^{5}$

\section{WHY BIOLOGICAL PRODUCT QUALITY CONTROL IS IMPORTENT}

Biological quality control always ensures the quality of the biological product which may be used in the human prospect. Blood is a perfect example of biological quality control. Biological products quality control is always ensure the safety of human life and also make a positive effect in the company profile. Biological products always have the risk of different type of contamination (Eg. microbiological contamination). Biological products like Vaccine, Immune sera ,Antitoxin, Antivenom, Toxoids, Blood and blood components, Allergenic products are manufactured outside and supplied to the desired places which strict quality control environment which include temperature and sterility. A small amount of contamination can destroy whole batch of product and cause big loss in terms of money and health both.

\section{RELATION BETWEEN PQC AND BIOLOGICAL QUALITY CONTROL}

In all type of quality control weather it is pharmaceutical quality control or biological product quality control it is always important that the desired product always meet the customer requirement. For maintaining the quality of products according to the regulatory authorities it is always essential that manufacturing units must maintain their quality control slandered.

- There are some factors which are commonly present in PQS and biological product quality control system.

- In both type of quality control system manufacturers must follow the guideline established by the different regulatory authorities.

- Both products are manufactured in the highly maintained sterilized environments.

- For every step validation process must be established.

- In both type of quality control system errors are must be reported.

\section{CONCLUSION}

There are many reasons that why quality control have very much importance in the field of pharmaceuticals and biological products industry. In some countries government and regulatory authorities regularly check and evaluate the quality control process and standards in the manufacturing facilities. A well designed quality control process can reduce the loss of the whole batch of product as well as it also reduces the loss of money. A good quality control process also increased the product rating in terms of sales and marketing. ${ }^{[6]}$

There are many pharmaceutical and biological products manufacturing facilities which make their own quality control procedures with the government regulatory procedures to ensure the best quality of their products.

The scope of quality control is very high in the future because with the time the manufacturing process are going to be more complex and there will be a pressure on manufacturing units to fulfill the need of medicines and biological products in the market. This need also put a pressure on manufacturing units for better quality control in short time to ensure the quality of their products.

\section{REFERENCES}

1. Margaret Rouse (2011)

[http://whatis.techtarget.com/definition/quality-control-QC ]

2. Kate Davies, Bristol-Myers Squibb : The Role of QC in the Pharmaceutical Industry

3. FDA guidelines on General Principles of Process Validation (May 1987)

4. Moy A. EMEA and FDA approaches on the ICH Q10 on pharmaceutical quality system. Pharma Times. 2009; 41 (8): 15-18.

5. WHO guidelines on good manufacturing practices (2011)

6. Alexandre Pignanelli, Joao Mario Csillag The Impact of Quality Management on Profitability: An Empirical Study THE flagship research journal OF international conference of the production and operations management society Volume June 2008 